\title{
Development of Ibuprofen Loaded Solid Dispersion with Improved Dissolution Using Tween 80 \& Span 80
}

Naila Shahrin*, Asma Huq

Department of Pharmacy, The University of Asia Pacific, Dhaka, Bangladesh

\begin{abstract}
To develop a novel dosage form of ibuprofen loaded solid dispersion with improved dissolution, formulations were developed using mixture of tween 80 \& span 80 with a sugar such as dextrose, icing sugar. Percentage of tween 80 \& span 80 was $10 \%$ \& $5 \%, 7.5 \% \& 7.5 \%, 5 \% \& 10 \%$ and amount of sugar was fixed $(1.2 \mathrm{~g})$. In-vitro dissolution study was conducted in phosphate buffer $(\mathrm{pH} 7.2)$ for 1 hour. Release property from formulations of both sugars was investigated. In both cases, enhanced release property was observed where the release was compared with pure ibuprofen powder. Formulations having same amount of tween 80 \& span 80 showed maximum release of drug. Formulations of icing sugar showed maximum release of drug within 1 hour time frame than the formulations of dextrose.
\end{abstract}

Keywords: Solid dispersion, Ibuprofen, Tween 80, Span 80, Dextrose, Icing sugar

\section{Introduction}

Ibuprofen is a non-steroidal antiiflammatory agent is widely used in the treatment of mild to moderated pain and fever. However, the bioavailability of ibuprofen is relatively low after oral administration, since it is practically insoluble in water. ${ }^{1}$ Thus increasing the aqueous solubility and dissolution rate of ibuprofen is of therapeutic importance.

${ }^{*}$ Corresponding Author

Email: shahrin_green@yahoo.com
One of the well established method for increasing the solubility and bioavailability of poorly water soluble drugs is solid dispersion system. ${ }^{2}$ It is a two component system consisting of a hydrophilic carrier in which the drug is incorporated. The incorporated drug in the hydrophilic carrier can be either molecularly dispersed or occurred as nano-crystals or amorphous nanoparticles. ${ }^{2}$ Furthermore, the drugs dispersed in polymeric carriers may achieve the highest levels of particle size reduction and surface area 
enhancement, resulting in improved dissolution rates. ${ }^{3}$

Another possible ways of enhancing the bioavailability of poorly watersoluble drugs is the application of surfactants. The effect of a surfactant on the bioavailability of poorly watersoluble drugs can be explained by three main mechanisms: (i) dispersion of drug, leading to an increase in contact; (ii) increased solubility of drug caused by the presence of micelles which may contain high concentrations of hydrophobic drug and (iii) facilitated transport of the drug from the solid phase to the aqueous phase, which can be caused by a number of phenomena, such as interaction of the surfactant with solid interfaces and interaction of the drug with single surfactant molecules. ${ }^{4}$

Many methods like spray drying, coprecipitation, co-evaporation and freeze dying are used for solid dispersion manufacturing; however, costly equipments are required along with complicated procedures. Apart from these techniques, fusion method is a method of choice because it is environmentally friendly, cost effective and can be easily scaled up for commercial purpose. ${ }^{5}$
The objective of present study was to improve the dissolution of ibuprofen by using tween 80 \& span 80 with dextrose \& icing sugar. The formulations were characterized by invitro dissolution study to compare the effects of polymer on dissolution profile.

\section{Materials and Methods Materials}

Ibuprofen was a gift sample from Incepta Pharmaceuticals Ltd., Bangladesh. Tween 80 was collected from ICl Limited, india and Span 80 was collected from BDH Chemicals Limited, England. Also commercial grade dextrose, icing sugar, di-sodium hydrogen phosphate and sodium hydroxide were used.

\section{Preparation of Solid Dispersion}

The solid dispersion was prepared by fusion method. Ibuprofen and tween 80 \& span 80 were accurately weighed and then placed in a glass vial. The vial was heated on a water bath by liquid paraffin to melt the drug \& polymer at the temperature of $100^{\circ} \mathrm{C}$. When drug \& polymer melted properly vial was withdrawn from the water bath and then dextrose/ icing sugar was added quickly with continuous stirring. After 5- 7 minute it cooled with 
continuous stirring. Formulation kept in dessicator for 12 hours. Finally the formulation was withdrawn from vials, crushed by mortar and pestle, passed through 150 micron sieve. Then formulations were transferred in the vials and stored in dessicator for further study.

\section{Preparation of Phosphate Buffer}

7.34gm di-sodium hydrogen

phosphate and 1gm sodium hydroxide were weighed and dissolved in small amount of distilled water, volume was adjusted to 1 liter with the same solvent to prepare 1 liter phosphate buffer. The $\mathrm{pH}$ of the buffer solution was adjusted using a $\mathrm{pH}$ meter.

\section{Preparation of Standard Curve of Ibuprofen}

Standard Ibuprofen solution was prepared in concentration range of 1 $\mathrm{mg} / \mathrm{l}$ to $12 \mathrm{mg} / \mathrm{l}$. in phosphate buffer $\mathrm{pH}$ 7.2. Then the absorbance of that standard solution of different concentration was observed in the double beam spectrophotometer (Shimadzu UV 1601, Shimadzu Corporation, Japan) at $221 \mathrm{~nm}$. From the observed absorbance, standard curve was made for the assay Ibuprofen.

\section{In vitro dissolution study of solid dispersion}

In vitro dissolution studies from the prepared formulations were carried out for 1 hour in phosphate buffer ( $\mathrm{pH}$ 7.2). $50 \mathrm{mg}$ equivalent crushed powder of ibuprofen solid dispersion of different formulations was subjected to the paddle dissolution method using 900 $\mathrm{ml}$ of phosphate buffer $(\mathrm{pH} 7.2)$ in dissolution apparatus (USP Type ॥ Dissolution Apparatus, VEEGO, India). The dissolution test was performed at $50 \mathrm{rpm}$ and the temperature was set at $37^{\circ} \mathrm{C} \pm 0.5^{\circ} \mathrm{C}$. At predefined interval, samples of $5 \mathrm{ml}$ were withdrawn, filtered and assayed by spectrophotometer (UVmini-1240, Shimadzu Corporation, Japan) at 221 $\mathrm{nm}$. After each sampling, equal volume $(5 \mathrm{ml})$ of fresh phosphate buffer $(\mathrm{pH}$ 7.2) was added to maintain sink condition.

\section{Result and Discussion}

The effect of tween 80 \& span 80 with dextrose \& icing sugar respectively on dissolution of ibuprofen from solid dispersion were studied. The potency of ibuprofen in prepared solid dispersions was analyzed by UV spectrophotometer and the results were within $99-101 \%$ in all cases 
which indicates uniform mixing of solid dispersions.

\section{$\%$ Release of Ibuprofen from} Formulations of Dextrose

In figure $1, \%$ release of drug from different formulations having tween 80 \& span 80 with dextrose and \% release of ibuprofen (drug only) were plotted against time. In case of pure drug, release was $54.18 \%$ after 1 hour. Release was increased from the solid dispersion of tween 80 \& span 80 . Formulation having same quantity of tween 80 \& span 80 showed maximum release $(80.56 \%)$ after 1 hour. In other two formulations of tween 80 \& span 80 , release of drug was almost same but increased compared to pure drug.

\section{$\%$ Release of Ibuprofen from}

\section{Formulations of Icing Sugar}

In figure 2, \% release of of drug from different formulations having tween 80 \& span 80 with icing sugar as well as formulation of pure drug were plotted against time. Release of drug significantly increased from solid dispersions. Formulation having same quantity of tween 80 \& span 80 showed maximum release (100.96\%) after 1 hour. Release of drug from other two formulations was almost same though significantly increased compared to pure drug.

\section{Discussion}

Dissolution improvement of ibuprofen from solid dispersion having tween 80 might be due to lowering of surface tension of drug-solvent and increased wettability of drug. $^{6}$ Formulations having higher concentration of span 80 than tween 80 showed relatively lower release of drug. It might be due to nature of solubility of tween 80 and span 80 . Tween 80 is soluble in water but span 80 is dispersible. ${ }^{7,8}$ Hence, tween 80 facilitated dissolution of drug in greater extent than span 80 . When tween 80 and span 80 were present in formulations with same ratio, drug release was maximum. It might be due to synergistic effect of solubilization of tween 80 and dispersion of span 80 in solvent.

Figure 3 shows that release of drug from formulations of solid dispersion having icing sugar was higher than formulations having dextrose. Icing sugar is fine powder but dextrose is crystalline or granular powder. ${ }^{9,} 10$ Icing sugar dissolves rapidly. ${ }^{9}$ Due to crystalline or granular structure, dextrose might not be dissolved faster Development of Ibuprofen Loaded Solid Dispersion with Improved Dissolution Using Tween 80 \& Span 80 


\section{Volume 1, Issue 1, Serial 1: August 2012}

as icing sugar. Moreover, dextrose has diluent as well as binder property and a tendency to harden. ${ }^{10}$ Hence, formulations of dextrose might require some energy to dissolve from crystalline or granular structure or from hardened mass. In formulations, dextrose \& icing sugar were used as diluent with solid dispersion of drugtween 80 \& span 80 . Since icing sugar dissolved rapidly, it also exposed drugtween-span solid dispersion to solvent rapidly which consequently facilitated higher release of drug within 1 hour time frame.

\section{Conclusion}

This study was to establish improved dissolution of ibuprofen by solid dispersion which is a poorly water soluble drug. Dissolution was studied considering different variables such as different ratio of tween 80 \& span 80 , dextrose \& icing sugar and results were recorded \& evaluated. Combination of tween 80 \& span 80 with icing sugar was found satisfactory for the development of solid dispersion of ibuprofen.

\section{Acknowledgement}

Authors are thankful to Incepta Pharmaceuticals Ltd., Dhaka, Bangladesh for the donation of
Ibuprofen. Authors are also thankful to the Department of Pharmacy, The University of Asia Pacific for their supports and cooperation.

\section{References}

1. Greenhalgh, D. J., Williams, A. C., Timmins, P., York, P., Solubility parameters as predictors of miscibility in solid dispersions. J. Pharm. Sci., 88, 1182-1190 (1999).

2. Chiou, W. L. and Riegelman, S., Pharmaceutical application of solid dispersion systems. J. Pharm. Sci., 73, 1281-1303 (1971).

3. Craig, D. Q. M., The mechanism of drug release from solid dispersion in watersoluble polymers. Int. J. Pharm., 231, 131-144 (2002).

4. Choi, Hun-Gon et al., Enhanced Oral Bioavailability of Flurbiprofen by Combined Use of Micelle Solution and Inclusion Compound. Arch. Pharm. Res., 33, 95-101 (2010).

5. Bhandari KH, Newa M, Kim JA, Yoo BK, Woo JS, Lyoo WS, Lim HT, Choi HG, Yong CS., 
Volume 1, Issue 1, Serial 1: August 2012

Preparation, characterization

Handbook of Pharmaceutical

and evaluation of coenzyme Excipients, $5^{\text {th }}$ edition, pp. 231

Q10 binary solid dispersions for (Great Britain: Pharmaceutical enhanced solubility and Press) (2006).

dissolution. Biol. Pharm. Bull., 30, 1171-1176 (2007).

6. Liu, L., Wang, X., Improved Dissolution of Oleanolic Acid with Ternary Solid Dispersions. AAPS Pharm. Sci. Tech., 8 (4), Article 113 (2007).

7. Rowe, Raymond C., Sheskey, Paul J., Owen, Sian C., Handbook of Pharmaceutical Excipients, $5^{\text {th }}$ edition, pp. 583 (Great Britain: Pharmaceutical Press) (2006).

8. Rowe, Raymond C., Sheskey, Paul J., Owen, Sian C., Handbook of Pharmaceutical Excipients, $5^{\text {th }}$ edition, pp. 714 (Great Britain: Pharmaceutical Press) (2006).

9. Rowe, Raymond C., Sheskey, Paul J., Owen, Sian C., Handbook of Pharmaceutical Excipients, $5^{\text {th }}$ edition, pp. 750 (Great Britain: Pharmaceutical Press) (2006).

10. Rowe, Raymond C., Sheskey, Paul J., Owen, Sian C., 
Volume 1, Issue 1, Serial 1: August 2012

Table 1: Formulations of Dextrose

\begin{tabular}{|l|l|l|l|}
\hline $\begin{array}{l}\text { Content } \\
(\mathrm{mg})\end{array}$ & $\mathrm{F} 1$ & $\mathrm{~F} 2$ & $\mathrm{F3}$ \\
\hline Ibuprofen & 500 & 500 & 500 \\
\hline Tween 80 & 200 & 150 & 100 \\
\hline Span 80 & 100 & 150 & 200 \\
\hline Dextrose & 1200 & 1200 & 1200 \\
\hline
\end{tabular}

Table 2: Formulations of Icing Sugar

\begin{tabular}{|l|l|l|l|}
\hline $\begin{array}{l}\text { Content } \\
(\mathrm{mg})\end{array}$ & $\mathrm{F} 4$ & $\mathrm{F5}$ & $\mathrm{F6}$ \\
\hline lbuprofen & 500 & 500 & 500 \\
\hline Tween 80 & 200 & 150 & 100 \\
\hline Span 80 & 100 & 150 & 200 \\
\hline Icing Sugar & 1200 & 1200 & 1200 \\
\hline
\end{tabular}

Figure 1: \% Release of drug from formulations of dextrose having tween 80 \& span 80

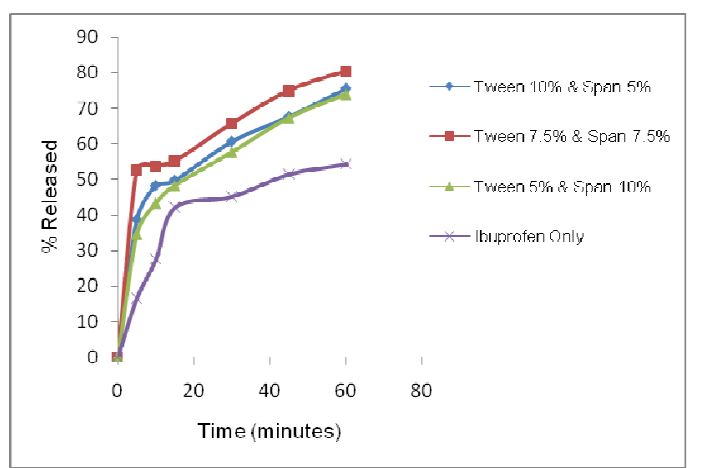

Figure 2: \% Release of drug from formulations of icing sugar having tween 80 \& span 80

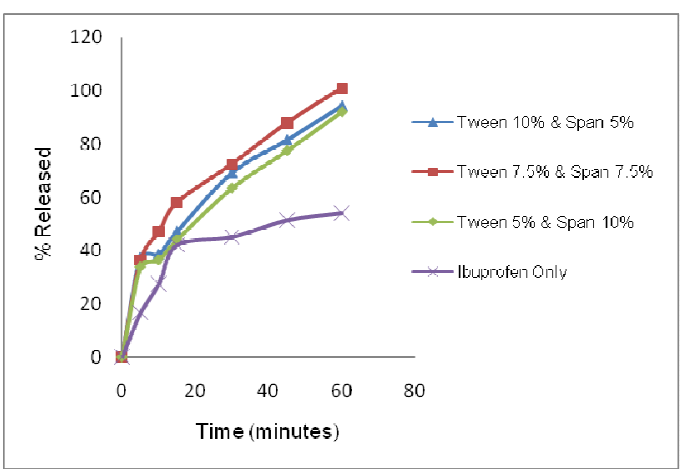

Figure 3: Comparison of \% release of drug from formulations of dextrose \& icing sugar

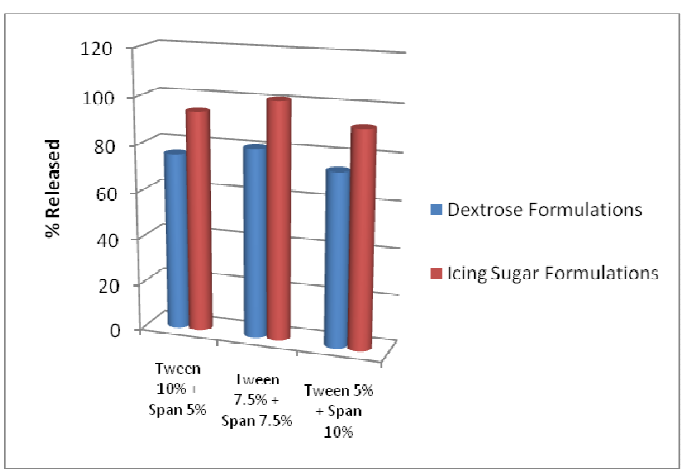

